Canadian Journal of Animal Science Revue canadienne de science animale

\title{
SHORT COMMUNICATION: Impact of low- and medium-oil corn dried distillers' grains plus solubles on growth performance of feedlot cattle
}

\begin{tabular}{|r|l|}
\hline Journal: & Canadian Journal of Animal Science \\
\hline Manuscript ID & CJAS-2016-0157.R2 \\
\hline Manuscript Type: & Short Communication \\
\hline Complete List of Authors: & $\begin{array}{l}\text { Ribeiro Jr., Gabriel; Lethbridge Research Centre, Agriculture and Agri-Food } \\
\text { Canada } \\
\text { Huenerberg, Martin; Agriculture and Agri-Food Canada, Lethbridge } \\
\text { Research Centre } \\
\text { Gibb, Darryl; Hi-Pro Feeds, } \\
\text { McAllister, Tim; Agriculture and Agri-Food Canada, Lethbridge Research } \\
\text { Centre }\end{array}$ \\
\hline Keywords: & \begin{tabular}{l} 
Beef, Nutrition, Protein, Ruminant, distillers grains \\
\hline
\end{tabular} \\
\hline
\end{tabular}


SHORT COMMUNICATION: Impact of low- and medium-oil corn dried distillers' grains plus solubles on growth performance of feedlot cattle

Gabriel O. Ribeiro Jr ${ }^{1}$., Martin Hünerberg ${ }^{1,2,3}$, Darryl Gibb², and Tim A. McAllister ${ }^{1,4}$

${ }^{1}$ Lethbridge Research and Development Centre, Agriculture and Agri-Food Canada, Lethbridge, Alberta, Canada T1J 4B1; ${ }^{2}$ Gowans Feed Consulting, Wainwright, Alberta, Canada T9W 1L2;

${ }^{3}$ Department of Animal Sciences, Ruminant Nutrition, University of Göttingen, Göttingen, Germany.

RIBEIRO ET AL. - LOW OR MEDIUM OIL CORN DDGS IN BEEF FEEDLOT DIETS

${ }^{4}$ To whom correspondence should be addressed: Lethbridge Research and Development Centre, Lethbridge, AB, T1J 4B1; phone: (403) 317-2240; fax: (403) 382-3156; email:

tim.mcallister@agr.gc.ca 


\begin{abstract}
During backgrounding, low-oil dried corn distillers' grains plus solubles (LO-DDGS) resulted in higher DM intake $(\mathrm{P}=0.002)$ and increased $\mathrm{ADG}(P=0.03)$ in steers compared to medium-oil (MO) DDGS. Inclusion of $20 \%$ DDGS tended $(P=0.06)$ to increase ADG compared to $10 \%$ DDGS. During finishing, MO-DDGS improved $(P=0.03)$ feed efficiency compared to LODDGS.
\end{abstract}

Key words: beef, carcass quality, corn dried distillers' grains plus solubles, efficiency

\begin{abstract}
Abbreviations: ADF, acid detergent fibre; ADG, average daily gain; CDO, corn distillers' oil; CP, crude protein; DDGS, corn dried distillers' grains with solubles; DM, dry matter; DMI, dry matter intake; EE, ether extract; G:F, Gain:Feed; LO-DDGS, low-oil corn dried distillers' grains plus solubles; MO-DDGS, medium-oil corn dried distillers' grains plus solubles; NDF, neutral detergent fibre; NEg, net energy for gain; NEm, net energy for maintenance; $\mathbf{O M}$, organic matter
\end{abstract}




\section{Introduction}

Due to the low crude protein $(\mathrm{CP})$ content of corn silage $[8.2 \pm 1.07 \%$ dry matter (DM) basis; NASEM, 2016] supplemental CP is needed to maintain optimum growth rate in cattle fed corn silage-barley grain based diets. Over the last 20 years, expansion of the North American grain ethanol industry has increased the supply dried distillers' grains plus solubles (DDGS) for feedlot cattle. Consequently, DDGS is the most common protein supplement in the North American beef industry (Renewable Fuels Association, 2015). As starch is almost completely removed from corn during ethanol fermentation nutrients in DDGS are concentrated nearly three-fold.

Corn DDGS has a relatively high oil content (10.7 $\pm 2.05 \%$ DM basis; NASEM, 2016) which can be used to produce biodiesel and as a result ethanol producers are increasingly using enhanced oil extraction technologies. By 2014 , approximately $85 \%$ of dry mills in the U.S. used enhanced extraction techniques and produced approximately 1.1 billion $\mathrm{kg}$ of corn oil (Renewable Fuels Association, 2015). . Differences in corn oil extraction technologies lead to variation in DDGS composition. Solvent-extraction of corn oil typically produces DDGS with an oil content of less than 3.0\% (DM basis; Saunders and Rosentrater, 2009), whereas ethanol plants that use mechanical extraction produce DDGS with an oil content of 6.0 to $9.0 \%$ (DM basis; He et al., 2014).

Feeding conventional corn DDGS ( $>10 \%$ EE; DM basis) to ruminants generally has a positive impact on growth performance, a finding which can partly be attributed to its higher energy content than cereal grains (Klopfenstein et al., 2008). He et al. (2014) found that replacement of 30\% of barley grain DM in a beef finishing feedlot diet with low-oil corn DDGS (7.1\%) decreased feed efficiency. This study was designed to examine the effect of LO-DDGS, 
$5.6 \%$ EE or MO-DDGS, $8.3 \%$ EE on feed intake, growth performance, and carcass quality of feedlot steers fed corn silage-barley grain diets.

\section{Materials and Methods}

All procedures and protocols were reviewed and approved by the Lethbridge Research Centre Animal Care Committee as per the guidelines of the Canadian Council on Animal Care. Animals, Experimental Design, and Diets

A combined growing (84 d) and finishing (112 d) study was conducted using 160 Angus crossbreed steers $[307 \pm 21.1 \mathrm{~kg}$ initial live body weight $(\mathrm{BW})]$. Upon arrival, steers were treated with Ultrabac 7/Somubac, (Zoetis Canada Inc., Kirkland, Quebec, Canada), Express FP5 (Boehringer Ingelheim Ltd. Burlington, Ontario, Canada) and Biomectin Pour-on (Merial Canada Inc., Baie D’Urfé, Quebec, Canada). Steers were implanted with Component TE-100 (100 mg trenbolone acetate, $10 \mathrm{mg}$ estradiol and $29 \mathrm{mg}$ tylosin tartrate; Elanco Animal Health, Guelph, Ontario, Canada) on 1 of the experiment and were re-implanted with Component TE-S (120 mg trenbolone acetate, $24 \mathrm{mg}$ estradiol and $29 \mathrm{mg}$ tylosin tartrate; Elanco Animal Health, Guelph, Ontario, Canada) $90 \mathrm{~d}$ before the end of the finishing experiment.

Steers were blocked by weight and randomly assigned to 1 of 16 pens ( $n=10$ steers per pen). Each pen was allocated to 1 of 4 treatments (Table $1 ; 4$ pens/treatment) consisting of two levels of oil iLO-DDGS (5.6\%), POET Biorefining, Groton, South Dakota, U.S. or MO-DDGS (8.3\%), Blue Flint Ethanol; Washburn, North Dakota, U.S and two DDGS inclusion levels 10\% or $20 \%$ (DM basis) during the growing period and $5 \%$ or $10 \%$ (DM basis) during finishing. Pens $(17 \mathrm{~m} \times 12.7 \mathrm{~m}$; with $1.2 \mathrm{~m}$ bunk space per head) were equipped with automatic waters and separated by porosity fences on two sides. After completion of the growing phase steers were 
transitioned to high-grain diets over $21 \mathrm{~d}$. The DDGS was substituted for barley grain which was processed to an index (vol. weight after processing/ vol. weight before processing $\times 100)$ of $80 \%$ $\pm 3 \%$.

\section{Growth Performance and Carcass Measurements}

Diets were prepared daily using a Beck 220 feed truck (Beck Implement Inc., Elgin, $\mathrm{MN})$. Steers were fed once daily at $1000 \mathrm{~h}$ to appetite targeting $<5 \%$ orts. Diets were balanced according to the recommendations of NASEM (2016) for growing and finishing feedlot cattle. Monensin sodium was included in all diets at $25 \mathrm{mg} / \mathrm{kg}$ (diet DM). Urea was added to diets with lower levels of DDGS to make them isonitrogenous. The quantity of feed offered was recorded daily and representative samples were collected weekly. Pen dry matter intake (DMI) was calculated as the difference between the amount of feed DM offered and refused. Steers were weighed before feeding on 2 consecutive days at the start and end of the growing and finishing phases, and every 21 and $28 \mathrm{~d}$, respectively. Weights were reported as shrunk weight $(\mathrm{BW} \times$ 0.96) and average daily gain (ADG) was calculated by dividing shrunk BW gain (final BW -initial BW) by days on feed. Carcass adjusted ADG was calculated as: Carcass adjusted ADG= [(Carcass weight/0.60) - initial BW] / days on feed. Feed conversion efficiency (Gain:Feed) was calculated by dividing ADG by DMI. Net energy gain of the diets was calculated based on growth performance as described by Ribeiro et al. (2016).

Steers were slaughtered at Cargill (High River, AB) and hot carcass weight (with kidneys removed), dressing percentage, back fat thickness, rib eye area, lean meat yield and quality grade determined. Liver abscess scores were determined according to the Elanco system.

Feed Sampling and Chemical Analysis 
Diets, orts, and ingredients were sampled weekly, oven dried at $55^{\circ} \mathrm{C}$ for $72 \mathrm{~h}$. Feed samples were composited by weigh period ( $21 \mathrm{~d}$ growing phase, $28 \mathrm{~d}$ finishing phase), ground through a $1 \mathrm{~mm}$ (Wiley mill; Arthur H. Thomas, Philadelphia, PA) and analytical DM was determined by drying at $135^{\circ} \mathrm{C}$ for $2 \mathrm{~h}$ (AOAC, 2005; method 930.15). Neutral detergent fibre (NDF) and acid detergent fibre (ADF), both expressed inclusive of residual ash were using amylase and sodium sulfite for the NDF analysis. Ether extract (EE) was determined according to AOAC (2005; method 2003.06). For the measurement of $\mathrm{CP}(\mathrm{N} \times 6.25)$ and starch, subsamples (5 g) were further ground with a ball grinder (Retsch MM 400; Retsch Inc., Newtown, PA). Nitrogen was quantified by flash combustion with gas chromatography and thermal conductivity detection (Carlo Erba Instruments, Milan, Italy). Starch content of diets and diet ingredients was determined by enzymatic hydrolysis of $\alpha$-linked glucose polymers.

\section{Statistical analyses}

Data were analyzed as completely randomized design with a $2 \times 2$ factorial treatment structure using the MIXED model procedure of SAS (SAS Inst. Inc., Cary, NC). Residual DDGS oil content, dietary inclusion level and their interaction were included as fixed effects. Pen was considered the experimental unit for DMI and growth performance parameters. Individual steer was the experimental unit for carcass measurements and liver scores. Initial BW was included as a covariate when significant. The GLIMMIX procedure was used to analyze liver scores and quality grade (AA, AAA or Prime). Significance was declared at $P<0.05$ with trends discussed at $0.05 \leq P \leq 0.10$.

\section{Results and Discussion}


The chemical composition of LO-DDGS was $94.3 \pm 0.12 \%$ OM, 5.0 $\pm 0.38 \%$ starch, $34.5 \pm 1.19 \%$ CP, $29.2 \pm 1.19 \%$ NDF, $7.7 \pm 0.41 \%$ ADF, $5.6 \pm 0.43 \%$ EE (Mean \pm SD, DM), while MO-DDGS averaged 95.2 $\pm 0.07 \%$ OM, $2.5 \pm 0.35 \%$ starch, $32.4 \pm 1.05 \% \mathrm{CP}, 36.9 \pm 1.47 \% \mathrm{NDF}$, $11.3 \pm 0.88 \%$ ADF, $8.3 \pm 0.22 \%$ EE (Mean \pm SD, DM). The level of oil in MO-DDGS was $2.7 \%$ higher than LO-DDGS. The calculated NEm and NEg were 3.3\% and 3.4\% lower respectively, for LO-DDGS than MO-DDGS (NASEM, 2016). Feeding LO-DDGS diets during the growing period increased DMI $(\mathrm{P}=0.002)$ and $\mathrm{ADG}(\mathrm{P}=0.03)$ of steers as compared to the MO-DDGS diets (Table 2). Steers offered 20\% DDGS diets tended to have higher ADG $(P=0.06)$ compared to those fed $10 \%$ DDGS diets. Feed efficiency and NEg of the diet were not affected $(P>0.10)$ by diet. Increased ADG in response to LO-DDGS in the growing phase was a result of increased DMI as feed efficiency was not improved. The numerically lower NEg associated with small changes in the composition of LO-DDGS as compared to MO-DDGS, suggests that the higher DMI may be related to the slightly higher CP content (15.8\% vs. $14.5 \%)$ and lower energy content of LO-DDGS diets, with steers compensating by eating more. An increase in DMI in the first $42 \mathrm{~d}$ of the backgrounding period was also observed by Galyean et al. (1993) when diet CP concentration increased from $14 \%$ to $16 \%$.

The DMI and ADG during the finishing period were not affected by DDGS type or inclusion level ( $P>0.10$; Table 3). However, feeding MO-DDGS to finishing steers improved Gain:Feed as compared to LO-DDGS $(\mathrm{P}=0.03)$. Consequently, a tendency $(P=0.09)$ for higher NEg content of the diet was observed for MO-DDGS (1.34 Mcal $/ \mathrm{kg})$ as compared to LO-DDGS $(1.28 \mathrm{Mcal} / \mathrm{kg})$. Although the differences in fat content among diets were small, improved feed efficiency in response to MO-DDGS coincided with its higher energy content. Similarly, Walter et al. (2010) observed improved feed efficiency in finishing steers as dietary fat increased as the 
level of corn DDGS was increased. In contrast, increasing the fat content of finishing diets by increasing inclusion of low oil corn DDGS decreased feed efficiency (He et al. 2014). The similarity in predicted NEg from TDN according to NASEM (2016) for LO- and MO-DDGS finishing diets (1.33 Mcal kg-1, Table 1), contrasts with the observed tendency for higher NEg in MO-DDGS compared to LO-DDGS finishing diets (1.33 vs. $1.28 \mathrm{Mcal} \mathrm{kg}^{-1}$, Table 3). Different feed efficiency responses between studies evaluating corn DDGS and in predicted vs. achieved NEg seems to depend on the chemical composition of the diet, and variation in DDGS quality due to differences in drying temperature or the amount of added solubles. Other factors such as the concentration of DDGS in the diet and interactions of DDGS with other dietary components can also influence its NEg value (Klopfenstein et al., 2008). Plant and sometimes batch specific factors can not only impact the oil content of DDGS, but also its fibre and protein digestibility. Interestingly, no differences $(P>0.10)$ in DMI, ADG, Gain:Feed or NEg were observed when finishing steers were fed $10 \%$ or $5 \%$ DDGS diets supplemented with urea (DM basis). This indicates that LO-DDGS and MO-DDGS could partially replace dry rolled barley plus urea without losses in ADG or feed efficiency in finishing diets.

Hot carcass weight, dressing percentage, back fat thickness, rib eye area, quality grades, lean meat yield and liver abscess scores were not affected $(P>0.10)$ by DDGS source or inclusion level (Table 3). He et al. (2014) also reported that replacing 30\% of the barley grain with LO-DDGS in a finishing diet did not affect the carcass traits of steers. It is interesting to note that numerically, carcasses of steers fed MO-DDGS were classified as Prime more than twice as often compared to LO-DDGS diets (7.8\% vs. 2.6\%). Compared to MO-DDGS, feeding LO-DDGS during backgrounding resulted in higher DMI and increased ADG, but did not improve feed efficiency. In finishing steers, MO-DDGS improved feed efficiency as compared 
to LO-DDGS. Thus, DDGS with lower oil content have higher feed value in growing diets while DDGS with higher oil content have greater feed value in finishing diets.

\section{Acknowledgment}

This study was conducted with funding from the North Dakota Corn Utilization Council, North Dakota Ethanol Utilization Council and U.S. Grains Council. The first author also gratefully acknowledges the CAPES Foundation from the Ministry of Education of Brazil for the postdoctoral fellowship (CAPES process BEX-9258-13-2). The authors thank Wendi Smart, Brant Baker, and Cody Barnson for their technical assistance. We also thank the barn staff of the Lethbridge Research and Development Centre for the care and management of the steers.

\section{References}

AOAC. 2005. Official Methods of Analysis, 18th ed. Assoc. Off. Anal. Chem., Gaithersburg, MD.

Galyean, M. L., Gunter, S. A., Malcolm-Callis, K. J., and Garcia. D. R. 1993. Effects of crude protein concentration in the receiving diet on performance and health of newly received beef calves. Clayton Livestock Res. Ctr. Prog. Rep. No. 88, New Mexico Agric. Exp. Sta., Las Cruces.

He, M. L., Xu, L., Yang, W. Z., Gibb, D. and McAllister, T. A. 2014. Effect of low-oil corn dried distillers' grains with solubles on growth performance, carcass traits and beef fatty acid profile of feedlot cattle. Can. J. Anim. Sci. 94: 343-347.

Klopfenstein, T. J., G. E. Erickson, and V. R. Bremer. 2008. BOARD-INVITED REVIEW: Use of distillers by-products in the beef cattle feeding industry. J. Anim. Sci. 86: 1223-1231. 
National Academies of Sciences, Engineering, and Medicine (NASEM). 2016. Nutrient Requirements of Beef Cattle, Eighth Revised Edition. Washington, DC: The National Academies Press. doi: 10.17226/19014.

Renewable Fuels Association (RFA). 2015. Going Global-2015 Ethanol Industry Outlook. http://www.ethanolrfa.org/resources/publications/outlook/

Ribeiro Jr., G. O., Swift, M. L., and McAllister, T. A. 2016. Effect of diastatic power and processing index on the feed value of barley grain for finishing feedlot cattle. J. Anim. Sci. (Just published) doi:10.2527/jas2015-0068

Saunders, J. A., Rosentrater, K. A. 2009. Properties of solvent extracted low-oil corn distillers dried grains with solubles. Biomass Bioenergy 33: 1486-1490.

Walter, L. J., Aalhus, J. L., Robertson, W. M., McAllister, T. A., Gibb, D. J., Dugan, M. E. R., Aldai, N. and McKinnon, J. J. 2010. Comparison of wheat or corn dried distillers grains with solubles on performance and carcass characteristics of feedlot steers. Can. J. Anim. Sci. 90: 259269. 
Table 1. Ingredients and chemical composition $(\mathrm{Mean} \pm \mathrm{SD}, n=4)$ of experimental diets.

\begin{tabular}{|c|c|c|c|c|c|c|c|c|}
\hline \multirow[b]{2}{*}{ Item } & \multicolumn{4}{|c|}{ Backgrounding Diets } & \multicolumn{4}{|c|}{ Finishing Diets } \\
\hline & $\begin{array}{c}10 \% \\
\text { LO-DDGS }\end{array}$ & $\begin{array}{c}20 \% \\
\text { LO-DDGS }\end{array}$ & $\begin{array}{c}10 \% \\
\text { MO-DDGS }\end{array}$ & $\begin{array}{c}20 \% \\
\text { MO-DDGS }\end{array}$ & $\begin{array}{c}5 \% \\
\text { LO-DDGS } \\
\end{array}$ & $\begin{array}{c}10 \% \\
\text { LO-DDGS }\end{array}$ & $\begin{array}{c}5 \% \\
\text { MO-DDGS }\end{array}$ & $\begin{array}{c}10 \% \\
\text { MO-DDGS }\end{array}$ \\
\hline \multicolumn{9}{|l|}{ Diet ingredient ( $\%$ of $\mathrm{DM})$} \\
\hline Corn silage & 60.00 & 60.00 & 60.00 & 60.00 & 10.00 & 10.00 & 10.00 & 10.00 \\
\hline Barley grain, dry-rolled & 24.30 & 15.00 & 24.30 & 15.00 & 79.65 & 75.00 & 79.65 & 75.00 \\
\hline Low-oil DDGS ${ }^{a}$ & 10.00 & 20.00 & - & - & 5.00 & 10.00 & - & - \\
\hline Medium-oil DDGS ${ }^{b}$ & - & - & 10.00 & 20.00 & - & - & 5.00 & 10.00 \\
\hline Supplement ${ }^{c}$ & 5.00 & 5.00 & 5.00 & 5.00 & 5.00 & 5.00 & 5.00 & 5.00 \\
\hline Urea & 0.70 & - & 0.70 & - & 0.35 & - & 0.35 & - \\
\hline \multicolumn{9}{|l|}{ Chemical composition (\% DM) } \\
\hline $\mathrm{OM}$ & $93.6 \pm 0.09$ & $93.4 \pm 0.08$ & $94.2 \pm 0.61$ & $94.0 \pm 0.30$ & $95.6 \pm 0.70$ & $95.7 \pm 0.54$ & $96.4 \pm 0.27$ & $96.3 \pm 0.33$ \\
\hline Starch & $32.3 \pm 0.91$ & $28.4 \pm 1.93$ & $32.8 \pm 1.40$ & $29.3 \pm 1.37$ & $50.1 \pm 2.85$ & $48.2 \pm 0.87$ & $51.6 \pm 2.27$ & $48.5 \pm 0.76$ \\
\hline $\mathrm{CP}$ & $15.9 \pm 0.83$ & $15.7 \pm 0.88$ & $14.1 \pm 0.36$ & $14.9 \pm 0.48$ & $13.4 \pm 0.66$ & $12.8 \pm 0.66$ & $13.2 \pm 1.25$ & $12.6 \pm 1.20$ \\
\hline NDF & $37.4 \pm 1.06$ & $39.0 \pm 2.17$ & $38.6 \pm 2.59$ & $40.1 \pm 2.46$ & $22.5 \pm 2.01$ & $21.2 \pm 2.33$ & $22.6 \pm 1.99$ & $23.8 \pm 1.85$ \\
\hline $\mathrm{ADF}$ & $17.4 \pm 0.89$ & $16.9 \pm 0.90$ & $17.0 \pm 0.39$ & $18.1 \pm 1.34$ & $8.0 \pm 1.02$ & $7.2 \pm 1.47$ & $8.2 \pm 0.87$ & $8.6 \pm 0.53$ \\
\hline Ether extract & $2.2 \pm 0.57$ & $2.7 \pm 0.26$ & $2.3 \pm 0.24$ & $2.9 \pm 0.25$ & $1.7 \pm 0.10$ & $1.8 \pm 0.07$ & $1.7 \pm 0.03$ & $2.2 \pm 0.15$ \\
\hline $\mathrm{NEm}\left(\text { Mcal kg of diet } \mathrm{DM}^{-1}\right)^{d}$ & 1.86 & 1.87 & 1.86 & 1.87 & 1.97 & 1.99 & 1.97 & 1.98 \\
\hline $\mathrm{NEg}\left(\text { Mcal kg of diet } \mathrm{DM}^{-1}\right)^{d}$ & 1.22 & 1.23 & 1.22 & 1.24 & 1.32 & 1.34 & 1.32 & 1.33 \\
\hline
\end{tabular}

Note: OM, organic matter; CP, crude protein; NDF, neutral detergent fibre; ADF, acid detergent fibre.

${ }^{a}$ Corn-based dried distillers' grain plus solubles (DDGS) with low residual oil content (chemical composition \% of DM Mean $\left.\pm \mathrm{SD}, n=4\right): 94.3 \pm 0.12 \mathrm{OM}$,

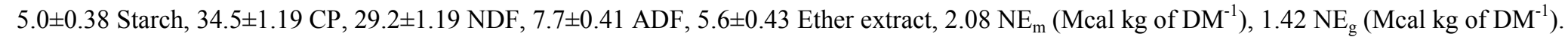

${ }^{b}$ Corn-based dried distillers' grain plus solubles (DDGS) with medium residual oil content (chemical composition \% of DM Mean \pm SD, $n=4$ ): $95.2 \pm 0.07$

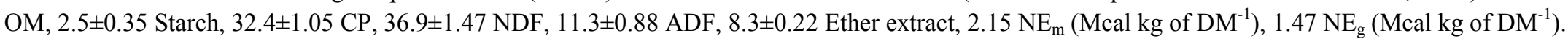

${ }^{c}$ Supplement contained (per kg) $572.02 \mathrm{~g}$ of ground barley, $250 \mathrm{~g}$ of calcium carbonate, $100 \mathrm{~g}$ of canola meal, $30 \mathrm{~g}$ of white salt, $25 \mathrm{~g}$ of molasses, $10 \mathrm{~g}$ of feedlot mineral, $10 \mathrm{~g}$ of canola oil, $2.32 \mathrm{~g}$ of Rumensin (Elanco Animal Health, Greenfield, IN; $25 \mathrm{mg}$ of monensin kg${ }^{-1}$ of DMI), and $0.66 \mathrm{~g}$ of vitamin E. It provided per kg DM: $15 \mathrm{mg}$ copper, $58 \mathrm{mg}$ zinc, $27 \mathrm{mg}$ manganese, $0.66 \mathrm{mg}$ iodine, $0.23 \mathrm{mg}$ cobalt, $0.29 \mathrm{mg}$ selenium, $4825 \mathrm{IU}$ vitamin A, $478 \mathrm{IU}$ vitamin D and $32 \mathrm{IU}$ vitamin $\mathrm{E}$.

${ }^{d} \mathrm{NEm}$, net energy for maintenance; $\mathrm{NE}_{\mathrm{g}}$, net energy for gain; were estimated according to NASEM (2016). 
Table 2. Growth performance and diet $\mathrm{NE}_{\mathrm{g}}$ of growing feedlot steers fed 10 or $20 \%$ (DM) of low- or medium-oil DDGS (LO-DDGS or MO-DDGS).

\begin{tabular}{|c|c|c|c|c|c|c|c|c|}
\hline \multirow[b]{2}{*}{ Item } & \multicolumn{2}{|c|}{ LO-DDGS } & \multicolumn{2}{|c|}{ MO-DDGS } & \multirow[b]{2}{*}{ SEM } & \multicolumn{3}{|c|}{$P$-value } \\
\hline & $10 \%$ & $20 \%$ & $10 \%$ & $20 \%$ & & DDGS & Level & DDGS $\times$ Level \\
\hline Shrunk initial BW (kg) & 294 & 294 & 296 & 296 & 3.4 & 0.42 & 0.98 & 0.99 \\
\hline Shrunk final BW (kg) & 415 & 423 & 415 & 416 & 4.3 & 0.37 & 0.31 & 0.45 \\
\hline Shrunk total BW gain $(\mathrm{kg})$ & 122 & 128 & 118 & 121 & 2.5 & 0.05 & 0.08 & 0.47 \\
\hline DMI $\left(\mathrm{kg} \mathrm{d}^{-1}\right)$ & 7.7 & 8.0 & 7.5 & 7.5 & 0.09 & $<0.01$ & 0.13 & 0.26 \\
\hline $\mathrm{ADG}(\mathrm{kg})$ & 1.43 & 1.52 & 1.39 & 1.42 & 0.029 & 0.03 & 0.06 & 0.35 \\
\hline Gain:Feed $\left(\mathrm{kg} \mathrm{kg}^{-1}\right)$ & 0.1855 & 0.1905 & 0.1870 & 0.1877 & 0.00342 & 0.86 & 0.42 & 0.55 \\
\hline Diet NEg $(\text { Mcal kg-1 })^{a}$ & 1.14 & 1.15 & 1.17 & 1.17 & 0.017 & 0.22 & 0.66 & 0.71 \\
\hline
\end{tabular}

Note: BW, body weight; Shrunk BW = BW × 0.96; DMI, dry matter intake; ADG, average daily gain.

${ }^{a} \mathrm{NEg}$, net energy for gain, was calculated based on performance data as described by Ribeiro et al. (2016). 
Table 3. Growth performance, diet NEg, carcass characteristics and liver abscesses of finishing feedlot steers fed 5 or $10 \%$ (DM) of lowor medium-oil DDGS (LO-DDGS or MO-DDGS).

\begin{tabular}{|c|c|c|c|c|c|c|c|c|}
\hline \multirow[b]{2}{*}{ Item } & \multicolumn{2}{|c|}{ LO-DDGS } & \multicolumn{2}{|c|}{ MO-DDGS } & \multirow[b]{2}{*}{ SEM } & \multicolumn{3}{|c|}{$P$-value } \\
\hline & $5 \%$ & $10 \%$ & $5 \%$ & $10 \%$ & & DDGS & Level & DDGS $\times$ Level \\
\hline Shrunk initial BW (kg) & 455 & 457 & 447 & 454 & 5.3 & 0.36 & 0.44 & 0.63 \\
\hline Shrunk final BW (kg) & 665 & 668 & 666 & 670 & 4.8 & 0.71 & 0.50 & 0.91 \\
\hline Shrunk total BW gain $(\mathrm{kg})$ & 212 & 214 & 213 & 217 & 4.8 & 0.71 & 0.50 & 0.91 \\
\hline $\operatorname{DMI}\left(\mathrm{kg} \mathrm{d}^{-1}\right)$ & 11.5 & 11.7 & 11.0 & 11.4 & 0.23 & 0.11 & 0.24 & 0.67 \\
\hline ADG (kg) & 1.87 & 1.90 & 1.88 & 1.92 & 0.043 & 0.71 & 0.50 & 0.91 \\
\hline Carcass adjusted ADG $(\mathrm{kg})$ & 1.86 & 1.89 & 1.90 & 1.93 & 0.048 & 0.43 & 0.53 & 0.99 \\
\hline Gain:Feed $\left(\mathrm{kg} \mathrm{kg}^{-1}\right)$ & 0.1613 & 0.1608 & 0.1680 & 0.1685 & 0.00290 & 0.03 & 0.99 & 0.87 \\
\hline Carcass adjusted Gain:Feed $\left(\mathrm{kg} \mathrm{kg}^{-1}\right)$ & 0.1613 & 0.1615 & 0.1720 & 0.1689 & 0.00351 & 0.02 & 0.70 & 0.64 \\
\hline Diet NEg $\left(\mathrm{Mcal} \mathrm{kg}^{-1}\right)^{a}$ & 1.28 & 1.28 & 1.33 & 1.34 & 0.029 & 0.09 & 0.97 & 0.89 \\
\hline \multicolumn{9}{|l|}{ Carcass characteristics $^{b}$} \\
\hline Carcass weight (kg) & 414.4 & 420.4 & 416.1 & 419.2 & 4.52 & 0.96 & 0.32 & 0.75 \\
\hline Dressing percentage & 60.2 & 60.4 & 60.7 & 60.3 & 0.25 & 0.35 & 0.70 & 0.25 \\
\hline Back fat (mm) & 23.0 & 22.6 & 24.7 & 23.0 & 1.50 & 0.49 & 0.48 & 0.67 \\
\hline Rib eye area $(\mathrm{cm})$ & 88.4 & 88.5 & 87.6 & 89.5 & 1.18 & 0.94 & 0.39 & 0.44 \\
\hline Lean meat yield $(\%)^{c}$ & 48.7 & 48.7 & 47.1 & 48.5 & 1.21 & 0.48 & 0.56 & 0.56 \\
\hline Prime $(\%)^{d}$ & 2.6 & 2.5 & 10.5 & 5.0 & - & 0.20 & 0.64 & 0.66 \\
\hline AAA $(\%)^{d}$ & 92.3 & 95.0 & 89.5 & 95.0 & - & 0.73 & 0.32 & 0.73 \\
\hline $\mathrm{AA}(\%)^{d}$ & 5.1 & 2.5 & 0.0 & 0.0 & - & 0.97 & 0.99 & 0.99 \\
\hline Abscessed livers (\%) & 43.6 & 55.0 & 47.4 & 40 & - & 0.39 & 0.99 & 0.32 \\
\hline Severely abscessed livers $(\%)^{e}$ & 10.3 & 12.5 & 5.3 & 10 & - & 0.40 & 0.42 & 0.67 \\
\hline
\end{tabular}

Note: BW, body weight; Shrunk BW = BW × 0.96; DMI, dry matter intake; ADG, average daily gain; Carcass adjusted ADG = [(Carcass weight/0.60) - initial BW] / days on feed. 
${ }^{a} \mathrm{NEg}$, net energy for gain, was calculated based on performance data as described by Ribeiro et al. (2016).

${ }^{b}$ Steers were fed for a total of $232 \mathrm{~d}(84 \mathrm{~d}$ growing phase $+21 \mathrm{~d}$ transitioning $+112 \mathrm{~d}$ finishing phase $+15 \mathrm{~d}$ to shipping).

${ }^{c}$ Lean meat yield $=57.96-0.027 \times($ carcass weight $)+0.202 \times($ rib eye area $)-0.703 \times($ back fat thickness $)$.

${ }^{d}$ Quality grades were determined according to Canadian Beef Grading Agency and expressed as percentage of total carcasses.

${ }^{e}$ Percentage of livers classified as $\mathrm{A}+(1$ or more active abscess $>2.5 \mathrm{~cm}$ diameter with inflammation of surrounding tissue). 